\title{
DESIGN SOCIAL E MEIO AMBIENTE: ESTUDO DE CASO NO BAIRRO SERRINHA
}

Adson Pinheiro Queiroz Viana

Universidade Federal do Ceará - UFC

Adson.queiroz12@gmail.com

Filipe Garcia Macambira

Universidade Federal do Ceará - UFC

f.macambira@yahoo.com
Anna Lucia dos Santos Vieira e Silva

Universidade Federal do Ceará - UFC

annalucialilu@gmail.com

Emilio Augusto Gomes de Oliveira

Universidade Federal do Ceara - UFC

emiliodesign@gmail.com

Carlos Eugenio Moreira de Sousa

Universidade Federal do Ceara - UFC

eugeniomoreira@dau.ufc.br

Resumo: A partir do século XIX, a responsabilidade com o meio ambiente tornou-se um aliado produtivo do Design, o qual passou a ser apresentado como uma área de conhecimento transversal e interdisciplinar. A partir desta perspectiva, surge o design social como uma possibilidade estratégica na busca de soluções inovadoras e abertas a novas possibilidades de ensino-aprendizado social. Com a tarefa de gerar sensibilização em relação à realidade de que nossos recursos naturais são finitos, investiga maneiras de melhorar a interação do homem com o meio ambiente. A partir dessa interface, este trabalho tem como objetivo avaliar o papel estratégico da atuação do design social como norteador de iniciativas estratégicas no bairro Serrinha, em Fortaleza, procurando entender e transformar a realidade urbana e social por meio da análise das diversas camadas de complexidade relacionadas à falta de saneamento básico e alagamentos periódicos de um assentamento informal, principais problemáticas que definem a situação da comunidade. Por meio de mutirões mensais, fundamentados na pesquisa-ação (TRIPP, 2005), alunos e professores do projeto de extensão "Varal - Laboratório de Iniciativas em Design Social" do "Canto - Escritório Modelo de Arquitetura e Urbanismo da UFC" e das Ciências Sociais somados a outras nove instituições públicas, privadas e não governamentais se unem à comunidade com o intuito de reverter à situação de forma cooperativa. Devido ao hábito comunitário de mau uso do espaço público, como por exemplo, o descarte inadequado de resíduos, às margens da Lagoa da Itaperaoba, outro fato se evidencia: a ausência de vínculo e pertencimento dos moradores do bairro em relação à área estudada. A partir deste diagnóstico, é identificada a necessidade de uma construção participativa de lugar. Com o esforço coletivo em descrever e reconhecer as problemáticas há uma condução para reorganização local e, durante um ano, com a aplicação de dispositivos estratégicos de design social e iniciativas táticas, o "lixão" torna-se uma praça modelo, com propostas de infraestrutura verde para o saneamento e 
drenagem local. A inclusão da comunidade no processo resolutivo faz com que as soluções para seu próprio benefício, e a produção de conhecimento repercutam em autonomia e sustentabilidade urbana. A Universidade Federal do Ceará (UFC) conclui o projeto com uma proposta executiva, acolhido pela prefeitura municipal para ser executado em 2016. Pode-se concluir que o projeto foi eficiente diante do desenvolvimento dos espaços criados, pois trouxe regeneração ao espaço e o bem-estar da comunidade, e propiciou referências para futuras intervenções em outros contextos sociais similares.

Palavras-chave: Design social, meio ambiente, sustentabilidade, regeneração urbana. 